\title{
PERBEDAAN PENGARUH METODE DRIL TERHADAP TEKNIK DASAR SEPAK TAKRAW
}

\section{DIFFERENT EFFECT OF THE DRIL METHOD ON BASIC TECHNIQUES OF SEPAK TAKRAW}

\author{
$1^{*}$ Resa Sukardi Masa, ${ }^{2}$ Ruskin, ${ }^{3}$ Arief Ibnu Haryanto \\ ${ }^{1,2,3}$ Program Studi Pendidikan Kepelatihan Olahraga, Fakultas Olahraga dan Kesehatan, Universitas Negeri \\ Gorontalo
}

Kontak koresponden: resasetter@gmail.com

\begin{abstract}
ABSTRAK
Penelitian ini bertujuan untuk mengetahui perbedaan pengaruh antara metode drill statis dan metode drill dinamis terhadap teknik dasar Sepak sila di Klub Takraw Keris Sakti. Penelitian ini menggunakan metode penelitian kuasi eksperimen yang sampelnya secara keseluruhan diambil dari populasi yang berjumlah 14 atlet yang dibagi menjadi dua kelompok. Kelompok pertama adalah kelompok latihan dril statis dan yang kedua adalah dril dinamis. Instrumen penelitian menggunakan menggunakan tes keterampilan dasar Sepak takraw tes kontrol (Ball Control). Adapun analisis data penelitian menggunakan uji normalitas, uji paired sampel $t$ tes, uji homogenitas varians, dan yang terakhir uji hipotesis menggunakan uji-t antar kelompok (independent t-test) menggunakan IBM SPSS Statistic 22. Hasilnya, mengacu pada Uji paired sample $\mathrm{t}$ test, bahwa ada pengaruh kedua metode dril tersebut terhadap teknik dasar Sepak takraw Sepak sila. Hasil dari independent t-test menyatakan bahwa kedua variasi metode dril tersebut tidaklah ada berbedaan yang berarti dari kedua rerata metode tersebut. Namun secara jumlah peningkatan rerata, metode dril dinamis lebih unggul daripada statis.
\end{abstract}

Kata Kunci: metode drill; sepak takraw

\section{ABSTRACT}

This study aims to determine the difference in the effect of the static drill method and the dynamic drill method on the basic techniques of sepak takraw, club takraw, keris sakti. This study used a quasi-experimental research method whose overall sample was taken from a population of 14 athletes who were divided into two groups. The first group is the static drill group and the second is the dynamic drill. The research instrument uses the basic skills test of sepak takraw, a control test (Ball Control). The research data analysis used normality test, paired sample t test, homogeneity of variance test, and finally hypothesis test using intergroup t-test (independent t-test) using IBM SPSS Statistic 22. The results refer to the paired sample $t$ test. , that there is an effect of the two drill methods on the basic techniques of sepak takraw in Sepak Sila. Hasih from the independent t-test stated that the two variations of the drill method were not significantly different from the mean of the two methods. However, in terms of the number of average increases, the dynamic drill method is superior to the static method.

Keywords: drill method; sepak takraw 


\section{Pendahuluan}

Olahraga pada masa kini sudah berkembang sangat pesat, masyarakat sudah semakin memahami pentingnya aktivitas keolahragaan baik untuk olahraga pendidikan, olahraga prestasi, olahraga masyarakat, maupun olahraga untuk kesehatan. Tujuan berolahraga beraneka ragam sesuai dengan kegiatan yang dilaksanakannya. Apabila tujuan berolahraga tersebut untuk berprestasi, maka tidak akan lepas dari peran pelatih yang handal dan juga harus banyak mengetahui metode-metode yang tepat dalam melatih atletnya.

Latihan dalam olahraga secara fisik, mental dan juga teknik hendaknya dapat mengikuti perkembangan dibidang keilmuan kepelatihan olahraga (Prasetyo, 2015) (Pernandes \& Sutisyana, 2018), banyak sekali metode-metode latihan fisik untuk meningkatkan kondisi fisik seperti latihan daya tahan, kecepatan, power, dan lain-lain secara umumnya (Pérez-Villalba et al., 2018) (Hidayat, 2019). Kemudian secara umumnya lagi masih ada metode latihan psikologis yang dapat meningkatkan kemauan untuk menang, meminimalisir kecemasan, atau bahkan supaya atlet menjadi lebih percaya diri akan kemampuannya (Barker \& Winter, 2014) (Haryanto et al., 2021). Namun, untuk olahraga prestasi semisalnya Sepak takraw mestinya memerlukan metode khusus untuk menyempurnakan tekniknya agar dapat optimal (Artyhadewa, 2017).

Jenis permainan olahraga Sepak takraw atau biasa disebut dengan Sepak raga merupakan olahraga yang populer dikalangan masyarakat Indonesia (Syam, 2019). Khususnya Gorontalo yang atlet putranya berhasil ikut menyumbangkan medali emas pada ajang Sea Games pada tahun 2019 (CNN Indonesia, 2019). Secara otomatis olahraga Sepak takraw pun populer di kalangan masyarakat Gorontalo. Olahraga Sepak takraw juga mempunyai gerakan-gerakan dasar dalam penerapannya misalkan sepakan yang terdiri dari berbagai jenis macam (Zulkifli et al., 2020) (Heriansyah \& Suhartiwi, 2021). Penelitian ini mengkhususkan pada teknik dasar sepak sila yang notabene sering dipakai pemain Sepak takraw dalam menerima dan juga mengontrol bola yang akan diuji mengunakan dua perlakuan metode dril yang berbeda dalam penerapannya.

Metode dril merupakan sebuah metode latihan secara berulang-ulang yang bertujuan untuk membiasakan atlet dalam melakukan suatu teknik (Ruslan \& Sangadji, 2021). Metode ini populer dikalangan pelatih maupun atlet agar dapat mendapatkan rasa nyaman dalam melakukan suatu gerakan (Pambudi \& Sulendro, 2021). Penelitian ini menggunakan dua metode dril yang berbeda. Pertama, yaitu metode dril statis yang pelaksanaannya pemain Sepak takraw menggunakan tembok sebagai titik sasaran. Kedua, yaitu metode dril dinamis yang pelaksanaannya pemain Sepak takraw bersama dengan pemain lain sebagai titik sasaran.

Penelitian terdahulu untuk penggunaan metode dril dalam Sepak Takraw dilakukan untuk melatih smes (Bastia \& Atiq, 2020) dan sepak mula bawah (Yulianto et al., 2021) yang mestinya berbeda dengan penelitian ini yang menggunakan sepak sila sebagai variabel terikatnya. Adapun urgensi dalam penelitian ini yaitu teknik dasar sepakan dalam olahraga sepak takraw merupakan komponen yang paling dominan bagi seorang atlet dalam melakukan suatu pertandingan, baik pada saat menyerang dan juga bertahan. Sepak takraw merupakan jenis olahraga dimana sasaran atau target pada saat menyerang maupun bertahan selalu berubah arah sehingga dibutuhkan kualitas yang lebik baik. 


\section{Metode}

Penelitian ini merupakan penelitian kuasi eksperimen two grup pretest-postest design yang populasinya secara keseluruhan dijadikan sampel berjumlah 14 atlet. Kedua anggota grup dipilih secara acak, kemudian masing-masing dari grup diberikan perlakuan yang berbeda antara metode dril statis dan metode dril dinamis. Instrumen penelitian menggunakan tes keterampilan dasar sepak takraw tes kontrol (Ball Control). Yaitu: 1) Bola dikontrol dengan menggunakan teknik dasar (sepak sila), 2) Bola yang jatuh ke tanah dapat dimainkan lagi, tapi penghitungan skor pada sepakan kedua dihitung dari awal dan berlaku pada setiap kali setelah bola jatuh sampai waktu habis, 3) Sepakan bola yang dihitung harus setinggi dada, 4) Luas lapangan untuk tes kontrol tidak dibatasi, 5) waktu yang dibatasi selama satu menit, 6) Setiap tiga kali sepekan dihitung dengan nilai satu dan seterusnya.

Analisis data penelitian menggunakan uji normalitas, uji paired sampel t tes, uji homogenitas varians, dan yang terakhir uji hipotesis menggunakan uji-t antar kelompok (independent t-test) menggunakan IBM SPSS Statistic 22.

\section{Hasil}

Temuan penelitian ini disajikan dengan data sebagai berikut:

Tabel 1. Data kelompok latihan dril statis

\begin{tabular}{cccc}
\hline No & Pretest $\left(\mathbf{X}_{\mathbf{1}}\right)$ & Postest $\left(\mathbf{X}_{\mathbf{1}}\right)$ & Gain Skor $(\mathbf{d})$ \\
\hline 1 & 21 & 45 & 24 \\
\hline 2 & 22 & 38 & 16 \\
\hline 3 & 30 & 50 & 20 \\
\hline 4 & 19 & 53 & 34 \\
\hline 5 & 35 & 40 & 5 \\
\hline 6 & 24 & 43 & 19 \\
\hline 7 & 26 & 47 & 21 \\
\hline
\end{tabular}

Tabel 2. Data kelompok latihan dril dinamis

\begin{tabular}{cccc}
\hline No & Pretest $\left(\mathbf{X}_{2}\right)$ & Postest $\left(\mathbf{X}_{2}\right)$ & Gain Skor $(\mathbf{d})$ \\
\hline 1 & 14 & 54 & 40 \\
\hline 2 & 14 & 37 & 23 \\
\hline 3 & 14 & 45 & 31 \\
\hline 4 & 18 & 42 & 24 \\
\hline 5 & 25 & 58 & 33 \\
\hline 6 & 20 & 45 & 25 \\
\hline 7 & 22 & 44 & 22 \\
\hline
\end{tabular}

Analisis deskriptif dalam penelitian ini bertujuan untuk memaparkan dan juga menggambarkan data penelitian, yang cakupannya yaitu jumlah data, nilai minimal, nilai maksimal, nilai rerata dan standar deviasi. Adapun outputnya sebagai berikut: 


\section{Descriptive Statistics}

\begin{tabular}{|l|r|r|r|r|r|}
\hline & N & Minimum & Maximum & Mean & Std. Deviation \\
\hline Pretest Statis & 7 & 19 & 35 & 25.29 & 5.589 \\
Postes Statis & 7 & 38 & 53 & 45.14 & 5.336 \\
Pretest Dinamis & 7 & 14 & 25 & 18.14 & 4.413 \\
Postes Dinamis & 7 & 37 & 58 & 46.43 & 7.185 \\
Valid N (listwise) & 7 & & & \\
\hline
\end{tabular}

Gambar 1. Outpot SPSS Deskripsi

Adapun hasilnya metode statis untuk Pretest nilai minimal adalah 19, nilai maksimal 35, rerata 25.29, dan standar deviasi 5.589. Hasil Postest nilai minimal adalah 38, nilai maksimal 53, rerata 45.14, dan standar deviasi 5.336. Hasil metode dinamis Pretest nilai minimal adalah 14, nilai maksimal 25, rerata 18.14, dan standar deviasi 4.413. Hasil metode dinamis Postest nilai minimal adalah 37, nilai maksimal 58, rerata 46.43, dan standar deviasi 7.185. Setelah melakukan analisis deskriptif maka dilakukan uji normalitas.

Uji normalitas dilakukan untuk menguji apakah data tersebut berdistribusi normal atau tidak. Uji normalitas dalam penelitian ini menggunakan statistik parametrik uji kologorovsmirnov dan uji shapiro-wilk.

Tests of Normality

\begin{tabular}{|c|c|c|c|c|c|c|c|}
\hline & \multirow[b]{2}{*}{ Kelompok } & \multicolumn{3}{|c|}{ Kolmogorov-Smirnov ${ }^{a}$} & \multicolumn{3}{|c|}{ Shapiro-Wilk } \\
\hline & & Statistic & df & Sig. & Statistic & df & Sig. \\
\hline \multirow[t]{4}{*}{ Hasil Sepak Sila } & Pretes Statis & .163 & 7 & $.200^{*}$ & .938 & 7 & .623 \\
\hline & Postes Statis & .118 & 7 & $.200^{*}$ & .980 & 7 & .961 \\
\hline & Pretest Dinamis & .255 & 7 & .189 & .877 & 7 & .215 \\
\hline & Postest Dinamis & .293 & 7 & .070 & .918 & 7 & .455 \\
\hline
\end{tabular}

*. This is a lower bound of the true significance.

a. Lilliefors Significance Correction

\section{Gambar 1. Outpot SPSS Uji Normalitas}

Berdasarkan otput IBM SPSS Statistic 22 tersebut diperoleh data yang menyatakan bahwa hasil Sig. dari output tersebut normal. Hal ini dikarenakan dalam uji kologorov-smirnov maupun uji shapiro-wilk Sig. > 0,05 (lebih dari 0,05). Setelah melakukan uji normalitas maka dilakukan uji paired sample t test.

Uji paired sample $\mathrm{t}$ test digunakan untuk mengetahui perbedaan sampel rerata yang terikat. Uji paired sample t test digunakan untuk menjawab apakah metode dril statis dan juga metode dril dinamis berpengaruh pada teknik dasar sepak sila beserta perbedaannya sebelum dan sesudah dilakukan metode dril statis dan juga metode dril dinamis.

Paired Samples Test

\begin{tabular}{|c|c|c|c|c|c|c|}
\hline \multicolumn{3}{|c|}{ Paired Differences } & & & \\
Mean & $\begin{array}{c}\text { Std. } \\
\text { Deviation }\end{array}$ & $\begin{array}{c}\text { Std. } \\
\text { Error }\end{array}$ & $\begin{array}{c}\text { 95\% Confidence Interval of the } \\
\text { Difference }\end{array}$ & $\mathrm{t}$ & df & $\begin{array}{c}\text { Sig. (2- } \\
\text { tailed) }\end{array}$ \\
\hline
\end{tabular}




\begin{tabular}{|c|c|c|c|c|c|c|c|c|c|}
\hline & & & & Mean & Lower & Upper & & & \\
\hline & $\begin{array}{l}\text { Pretes Statis - } \\
\text { Postes Statis }\end{array}$ & -19.857 & 8.707 & 3.291 & -27.910 & -11.805 & -6.034 & 6 & .001 \\
\hline Pair 2 & $\begin{array}{l}\text { Pretes Dinamis - } \\
\text { Postes Dinamis }\end{array}$ & -28.286 & 6.626 & 2.504 & -34.414 & -22.158 & -11.294 & 6 & .000 \\
\hline
\end{tabular}

\section{Gambar 3. Outpot SPSS Uji Paired Sample Test}

Berdasarkan otput IBM SPSS Statistic 22 tersebut diperoleh data paired sample t test untuk pair 1 dan pair 2 diperoleh nilai Sig. (2-tailed) 0.001 dan $0.000<0,05$, maka dapat disimpulkan ada perbedaan rerata untuk pretes dan postes hasil metode dril statis dan dinamis. Kesimpulannya yaitu bahwa ada pengaruh metode dril statis dan juga metode dril dinamis untuk meningkatkan keampuan sepak sila.

Uji homogenitas varians dilakukan untuk mengetahui apakah data dari penelitian ini homogen atau tidak yaitu dengan One-Way ANOVA.

\section{Test of Homogeneity of Variances}

\begin{tabular}{|c|c|c|c|}
\hline Levene Statistic & $\mathrm{df} 1$ & $\mathrm{df} 2$ & Sig. \\
\hline .478 & 1 & 12 & .502 \\
\hline
\end{tabular}

Gambar 4. Outpot SPSS Uji Homogenitas

Berdasarkan otput IBM SPSS Statistic 22 tersebut diperoleh data yang menyatakan bahwa hasil Sig. dari output tersebut homogen. Hal ini dikarenakan dalam uji One-Way ANOVA Sig. > 0,05 (lebih dari 0,05). Hal terakhir yang dilakukan yaitu menggunakan uji independent $t$ test

Uji hipotesis (independent t-test) digunakan untuk mengetetahui rerata dua sampel yang tidak berpasangan untuk membandingkan metode statis dan metode dinamis setelah diterapkan beserta perbedaan rerata hasil dari metode statis dan metode dinamis.

Independent Samples Test

\begin{tabular}{|c|c|c|c|c|c|c|c|c|c|c|}
\hline & \multicolumn{2}{|c|}{$\begin{array}{l}\text { Levene's Test } \\
\text { for Equality of } \\
\text { Variances }\end{array}$} & \multicolumn{7}{|c|}{$\mathrm{t}$-test for Equality of Means } \\
\hline & & \multirow[b]{2}{*}{$\mathrm{F}$} & \multirow[b]{2}{*}{ Sig. } & \multirow[b]{2}{*}{$\mathrm{t}$} & \multirow[b]{2}{*}{ df } & \multirow{2}{*}{$\begin{array}{l}\text { Sig. (2- } \\
\text { tailed) }\end{array}$} & \multirow{2}{*}{$\begin{array}{c}\text { Mean } \\
\text { Difference }\end{array}$} & \multirow{2}{*}{$\begin{array}{l}\text { Std. Error } \\
\text { Difference }\end{array}$} & \multicolumn{2}{|c|}{$\begin{array}{l}95 \% \text { Confidence } \\
\text { Interval of the } \\
\text { Difference } \\
\end{array}$} \\
\hline & & & & & & & & & Lower & Upper \\
\hline $\begin{array}{l}\text { Hasil } \\
\text { Sepak Sila }\end{array}$ & $\begin{array}{l}\text { Equal variances } \\
\text { assumed }\end{array}$ & 478 & .502 & -.380 & 12 & .711 & -1.286 & 3.383 & -8.656 & 6.084 \\
\hline & $\begin{array}{l}\text { Equal variances not } \\
\text { assumed }\end{array}$ & & & -.380 & 11.075 & .711 & -1.286 & 3.383 & -8.725 & 6.153 \\
\hline
\end{tabular}

Gambar 5. Outpot SPSS Uji Independen t-tes

Berdasarkan otput IBM SPSS Statistic 22 tersebut diperoleh data yang menyatakan bahwa hasil nilai Sig. (2-tailed) $0.711>0.05$, maka dapat disimpulkan bahwa tidak ada perbedaan rerata hasil metode statis dan metode dinamis setelah diterapkan. Namun, ada 
perbedaan tipis antara rerata metode statis yang mempunyai nilai 45.14 dan metode dinamis yang mempunyai nilai 46.43, sehingga metode dinamis lebih besar 1.29 daripada metode statis.

\section{Pembahasan}

Pengujian hipotesis yang diajukan pada penelitian ini telah menghasilkan suatu temuan. Program latihan dalam penelitian ini, menerapkan bentuk latihan variasi sepak sila menggunakan sasaran tembok (dril statis) dan variasi sepak sila berpasangan (dril dinamis) terhadap peningkatan kemampuan menimang bola dengan sepak sila. Hal ini seperti temuan penelitian yang menyatakan bahwa metode dril ini dapat meningkatkan kemampuan sepakan dalam olahraga Takraw (Pambudi \& Sulendro, 2021). Penelitian lain juga menyebutkan bahwa melalui metode yang benar, maka teknik dasar Sepak takraw ini akan mengalami peningkatan (Suprayitno, 2018). Sebelum pelaksanaan penelitian, terlebih dahulu memberikan pengenalan bentuk latihan terhadap sampel yang dijadikan obyek penelitian. Sehingga mereka yang ikut dalam penelitian ini paham dan tau betul akan tujuan serta manfaat dari program yang mereka jalani selama proses penelitian

\section{Kesimpulan}

Berdasarkan hasil analisis data, deskripsi, pengujian hasil penelitian, dan pembahasan, dapat diambil kesimpulan bahwa: Terdapat perbedaan hasil latihan variasi sepak sila statis dan variasi latihan sepak sila dinamis terhadap peningkatan kemampuan menimang bola dengan sepak sila pada Atlet Keris Sakti Provinsi Gorontalo.

\section{Referensi}

Artyhadewa, M. S. (2017). Pengembangan model permainan sepak takraw sebagai pembelajaran pendidikan jasmani bagi anak SD kelas atas. Jurnal Keolahragaan, 5(1). https://doi.org/10.21831/jk.v5i1.12804

Barker, S., \& Winter, S. (2014). The practice of sport psychology: A youth coaches' Perspective. International Journal of Sports Science and Coaching. https://doi.org/10.1260/17479541.9.2.379

Bastia, B., \& Atiq, A. (2020). Pengaruh Drill Training Dengan Media Bola Gantung Terhadap Kemampuan Smash Kedeng Sepak Takraw. Jurnal Pendidikan Jasmani Khatulistiwa, 1(1). https://doi.org/10.26418/jpjk.v1i1.43578

CNN Indonesia. (2019). Sepak Takraw Raih Emas untuk Indonesia di SEA Games 2019.

Haryanto, A. I., Gani, A. A., Ramadan, G., Samin, G., Fataha, I., \& Kadir, S. S. (2021). Shooting Athlete Mental Training. JUARA: Jurnal Olahraga, 6(1). https://doi.org/https://doi.org/10.33222/juara.v6i1.1188

Heriansyah, \& Suhartiwi, A. (2021). Permainan Sepak Takraw Sejarah, Teknik Dasar, Peraturan Pertandingan dan Perwasitan. CV. Jakad Media Publishing.

Hidayat, S. (2019). Kesegaran Jasmani Siswa 10-12 Tahun Se-Kota. Jambura Journal of Sports Coaching. 
Pérez-Villalba, M., Vilanova, A., \& Soler Prat, S. (2018). Sport labor market and gender: A comparative study on working conditions of Physical Activity and Sport Science graduates by Catalan universities. Revista de Humanidades (SPAIN), 34. https://doi.org/10.5944/rdh.34.2018.19731

Pernandes, A., \& Sutisyana, A. (2018). Pengaruh Latihan Bola Gantung Terhadap Kemampuan Smash Kedeng Dan Smash Gulung Dalam Permainan Sepak Takraw Pada Atlet PSTI Kabupaten Lebong. KINESTETIK, 2(1). https://doi.org/10.33369/jk.v2i1.5741

Prasetyo, Y. (2015). Kesadaran Masyarakat Berolahraga untuk Peningkatan Kesehatan dan Pembangunan Nasional. MEDIKORA. https://doi.org/10.21831/medikora.v11i2.2819

Rizky Dhisma Agung Pambudi, \& Sulendro, S. (2021). Pengaruh Latihan Drill Servis Terhadap Ketepatan Servis Samping Olahraga Sepak Takraw PSTI Panggul Trenggalek. SPRINTER: Jurnal Ilmu Olahraga, 2(2). https://doi.org/10.46838/spr.v2i2.122

Ruslan, R., \& Sangadji, F. (2021). ZIG-ZAG Running Exercises for Ball Drill Skills. Jambura Journal of Sports Coaching, 3(1).

Suprayitno. (2018). Hasil Belajar Sepak Sila Permainan Sepak Takraw (Studi Ekperimen tentang Pengaruh Gaya Mengajar Dan Kemampuan Motorik pada Mahasiswa PJKR FIK Unimed). Jurnal Ilmu Keolahragaan, 17(1).

Syam, A. (2019). Analisis Kemampuan Inteligensi Atlet Cabang Olahraga Sepak Takraw Provinsi Gorontalo. Jambura Journal of Sports Coaching, 1(2). https://doi.org/10.37311/jjsc.v2i1.2385

Yulianto, T., Priyono, A., \& Suhaemi, M. E. (2021). Pengaruh Metode Drill Terhadap Keterampilan Sepak Mula Bawah dalam Permainan Sepak Takraw pada Siswa Ekstrakurikuler SDN Sembung 01 Larangan Brebes. JOURNAL RESPECS, 3(1). https://doi.org/10.31949/jr.v3i1.2790

Zulkifli, Z., Yani, A., Kamarudin, Sasmarianto, Alficandra, \& Henjilito, R. (2020). Pengaruh Dua Gaya Mengajar Mosston dan Dukungan Motor Ability Mahasiswa Terhadap Hasil Belajar Teknik Dasar Sepak Takraw. Journal Sport Area, 5(1). https://doi.org/10.25299/sportarea.2020.vol5(1).4693 